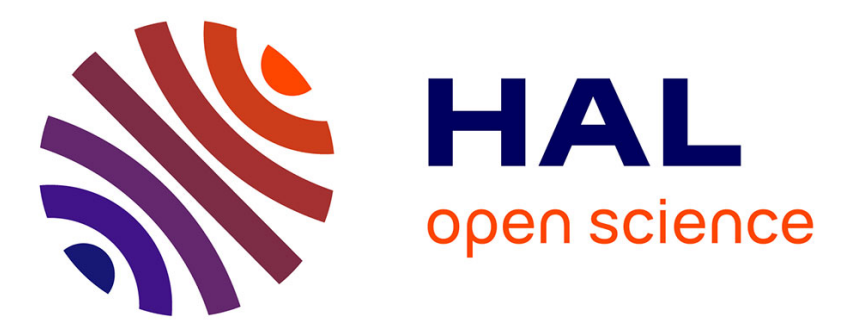

\title{
An integrated framework for planning of recycling activities in electrical and electronic sector
}

\author{
Muhammad Shahzad Abu Bakar, S Rahimifard
}

\section{To cite this version:}

Muhammad Shahzad Abu Bakar, S Rahimifard. An integrated framework for planning of recycling activities in electrical and electronic sector. International Journal of Computer Integrated Manufacturing, 2008, 21 (06), pp.617-630. 10.1080/09511920801905425 . hal-00513399

\section{HAL Id: hal-00513399 \\ https://hal.science/hal-00513399}

Submitted on 1 Sep 2010

HAL is a multi-disciplinary open access archive for the deposit and dissemination of scientific research documents, whether they are published or not. The documents may come from teaching and research institutions in France or abroad, or from public or private research centers.
L'archive ouverte pluridisciplinaire HAL, est destinée au dépôt et à la diffusion de documents scientifiques de niveau recherche, publiés ou non, émanant des établissements d'enseignement et de recherche français ou étrangers, des laboratoires publics ou privés. 


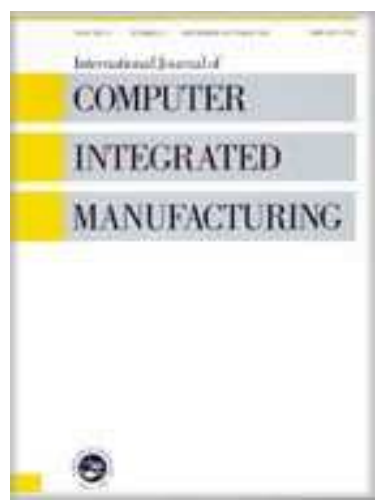

\section{An integrated framework for planning of recycling activities in electrical and electronic sector}

\begin{tabular}{|c|c|}
\hline Journal: & International Journal of Computer Integrated Manufacturing \\
\hline Manuscript ID: & TCIM-2007-IJCIM-0094.R1 \\
\hline Manuscript Type: & Original Manuscript \\
\hline $\begin{array}{r}\text { Date Submitted by the } \\
\text { Author: }\end{array}$ & 29-Nov-2007 \\
\hline Complete List of Authors: & $\begin{array}{l}\text { Abu Bakar, Muhammad; Loughborough University, Wolfson School } \\
\text { of Mechanical and Manufacturing Engineering } \\
\text { Rahimifard, S; Loughborough University, Dept of Manufacturing } \\
\text { Engineering }\end{array}$ \\
\hline Keywords: & ENVIRONMENT, SUSTAINABLE DEVELOPMENT \\
\hline Keywords (user): & WEEE, Recycling Process Planning \\
\hline
\end{tabular}

\section{scholarONE \\ Manuscript Central}




\title{
An integrated framework for planning of recycling activities in electrical and electronic sector
}

\author{
M.S. ABU BAKAR and S. RAHIMIFARD
}

Postal address of affiliations:

${ }^{\text {a }}$ The Centre for Sustainable MAnufacturing and Reuse/Recycling Technologies (SMART),

Wolfson School of Mechanical and Manufacturing Engineering,

Loughborough University,

Loughborough, LE11 3TU,

$U K$.

Corresponding author: Muhammad Shahzad Abu Bakar

Complete correspondence address:

The Centre for Sustainable MAnufacturing and Reuse/Recycling Technologies (SMART),

Wolfson School of Mechanical and Manufacturing Engineering,

Loughborough University,

Loughborough, LE11 3TU,

$U K$.

Tel: $\quad$ +44 (0) 1509227683

Fax: $\quad+44(0) 1509227648$

Email: m.s.abu-bakar@lboro.ac.uk 


\begin{abstract}
In Europe 7.3 million tonnes of Waste Electrical and Electronic Equipment (WEEE) were created in 2002, and the fact that growth rate of WEEE is 3-5\% per annum with a significant amount of this waste used to be dumped into landfills without any pre-treatment, has resulted in the introduction of European WEEE directive. The directive requires companies who manufacture or import electrical and electronic equipment to take financial and legal responsibility for its environmental-friendly recovery and recycling. The current recycling applications of WEEE are often developed on ad hoc basis and mainly attributable to the hidden economic value within used products. However, at present the recycling facilities are faced with the challenge to improve WEEE recycling activities to ensure that a larger proportion of components and materials are being recovered at a reasonable cost and yet at the same time legislative requirements are being met. A major assertion made in the research reported in this paper is that a systematic framework is needed to aid the decision making involved in adopting the best possible end-of-life strategies for WEEE. The paper presents one such integrated framework for the planning of the processes involved in the recycling of WEEE. Based on this framework a Computer-Aided Recycling Process Planning $(\mathrm{CARPP})$ system which generates bespoke recycling process plans for WEEE has been developed which is also described and its functionality demonstrated using a typical WEEE product.
\end{abstract}

Keywords: WEEE, Recycling Process Planning, Electrical and Electronic Equipment, Recycling

\title{
1 Introduction
}

Waste from electrical and electronic equipment has been identified as one of the fastest growing sources of waste in Europe (Cui and Forssberg 2003). Technological innovation and shorter product life cycles of Electrical and Electronic Equipment (EEE) coupled with its increasing use in daily life are contributing to this high rate of growth. Although it represents only $5 \%$ of the municipal waste stream, with an average growth rate of three times greater than that of municipal waste, the quantity of WEEE is expected to double over the next decade. In addition, WEEE is 
non-homogenous and complex in terms of materials and components and often includes highly toxic materials such as chlorinated and brominated flame retardants, toxic metals, acids, mercury, lead and cadmium. With such hazardous elements, WEEE can cause serious environmental and health problems during disposal if not pre-treated (European Commission 2000, Macauley et al. 2003). The consumption of scarce materials in the manufacture of EEE and its disposal to scarce landfill sites along with environmental and health problems caused by WEEE have raised concerns among governments, environmentalists, manufacturers and consumers. As a result, the European Commission introduced the WEEE directive requiring producers to take responsibility for the waste management of their products. The scope of this Producer Responsibility directive targets producers, distributors, consumers and all parties involved in the treatment of WEEE and it aims to reduce the amount of WEEE going to landfills, increase reuse, recycling and other forms of recovery, and consequently reduce the environmental impacts associated with the End-of-Life (EOL) phase of EEE (European Commission 2003). In its simplest sense the directive requires EEE manufacturers to finance collection, treatment and recycling/recovery of separately collected WEEE to the specific treatment standards and meet recovery/recycling targets of $50-80 \%$ by weight depending on the type of EEE.

Historically in the UK, WEEE has either not been separately collected from other forms of waste, or it has not been properly treated prior to reprocessing (with the exception of refrigeration equipment, cathode ray tubes, and gas discharge lamps). Currently, the recovery treatment of WEEE is mainly driven by economical considerations and typically based on the capabilities and available resources within a specific EEE recovery facility, without any detailed assessment of the environmental benefits of such recycling activities. Furthermore, these recycling activities are solely focused on the reclamation of the most valuable components and materials, with a substantial amount of waste still being sent to landfill in the form of shredder residue.

The WEEE directive is impacting recycling facilities mainly in two ways. Firstly, it puts constraints on how they operate in terms of treatment and disposal of equipment to make them more environmental-friendly. Secondly, it is forcing them to develop and establish profit making opportunity from recycling of WEEE. In the wake of such legislative pressures, the recycling 
facilities need to improve the value recovery from WEEE recycling to ensure that a larger proportion of components and materials are being recovered from WEEE at a reasonable cost. This highlights the need for a systematic framework to aid the decision making involved in the selection of the best possible EOL strategy for WEEE.

This paper presents one such framework to generate bespoked recycling process plans for the treatment of specific waste streams in WEEE. The initial sections of the paper present an overview of WEEE arising and outline the current shortcomings with respect to the recycling and disposal of WEEE in the UK. The latter sections present an integrated recycling process planning framework together with an associated computer-aided recycling process planner which generates the bespoke recycling process plans to improve the ecological and economical performance of WEEE recycling. Finally, the functionality of the CARPP system is demonstrated through a case study of a refrigerator.

\section{An overview of WEEE arising in the UK}

Under the WEEE directive all EEE has been grouped into one of ten categories. Estimates of the total quantity of WEEE arising in the UK vary between 650 - 950K tonnes per year. Households provide the majority of EOL appliances. A smaller number come from appliance retailers and servicers, who typically take back old major appliances when installing new ones. A third source of used appliances is so-called "demand side management" or "early turn-in" programs where electric utilities give their customers incentives to turn in older, less efficient appliances. A report compiled by Industry Council of Electronic Equipment Recycling (ICER) based on the sales data from 2003 highlights the contribution of individual categories of equipment towards the total WEEE arising in the UK, as summarised in Table 1. Large household appliances make the largest contribution (69\%) towards the weight of household WEEE, whereas in terms of number of appliances discarded small household appliances make the largest contribution (31\%) (ICER 2005).

\section{[Insert Table 1]}


In addition to the variation in weights and numbers towards the total waste, different categories of EEE have different material compositions. For example, large household appliances consist mainly of steel (at around $61 \%$ by mass on average), whereas consumer electronic products consist largely of glass, ceramics, and plastics (at around 65\%). The material composition of different appliances within the same category can also vary substantially. For example in consumer equipment category, hi-fi equipment does not usually contain the glass or wood contained in the cathode ray tubes and casings of televisions, or in the case of white goods, fridges and freezers do not usually contain the concrete contained as a balancing counter-weight in washing machines. It is therefore argued that due to this variety of materials mix and the range of routes through which WEEE may be discarded; the recycling of WEEE is more complex than the recycling of conventional materials such as steel, aluminum and paper in vehicles and packaging products. In addition, the complexity of materials contained in WEEE does not allow a generic EOL option to be used for different products and requires initial processing and customisation of EOL recycling strategies for individual EEE products.

\section{Current shortcomings in WEEE recycling}

At present, a limited volume of WEEE is collected and sent to recycling facilities in the UK. The authors consider the following as some of the current shortcomings in WEEE recycling in the UK.

- Recovery practices driven by economical factors: Historically the metal dominated products (white goods) have been targeted for recycling which are often processed together with other metallic streams (like automobiles) to recover the ferrous metals. Such recycling activities have primarily been undertaken for commercial reasons to obtain the value from secondary metals without any consideration to the environmental impact of substantial quantities of waste being sent to landfill sites as shredder residues without any treatment.

- Lack of product data to facilitate recycling: Product structure and material composition information is a prerequisite for making an informed decision about selecting a recycling strategy for a particular product. However, currently in most cases access to this product data 
is not available to recyclers, resulting in inconsistencies and inefficiencies in recovery treatment of WEEE.

- Lack of manual disassembly to recover reusable parts and materials: The manual disassembly of parts and materials has never been attempted by the majority of recovery facilities mainly due to the lack of awareness among recyclers about the potential value of reuse through repair and remanufacturing. Although, for the vast majority of WEEE the opportunities for environmentally justified reuse and remanufacture are very limited due to technological obsolescence and high manual dismantling cost, such end-of-life options could still provide better solution than material recycling route.

- Contaminations in post-shredder material streams: The value of many post-shredder material streams depends on the material purity. Inefficiencies in the current shredding and separation processes are responsible for the contaminations in post-shredder material streams. One example is copper polluting the scrap steel, which alters the properties of the melted steel. This has such a negative impact on the value of scrap steel that some of the shredding operators in the UK employ hand-pickers to remove copper wires from scrap steel (Edwards et al. 2006).

- Inefficiencies in ad hoc applications of WEEE recovery: Currently there is little consistency regarding WEEE recycling due to lack of formal procedures to determine the best course of action for individual products. The recovery treatment of WEEE is mainly based on the capabilities and available resources within a specific recovery facility. The complexity of materials contained within each product and the huge variety of products in EEE, make ad hoc applications of WEEE recycling highly ineffective in terms of both ecological and economical considerations.

The existing and future concerns in terms of legislative compliance together with the competitive business environment for different stakeholders in WEEE recovery chain highlight the need for a systematic and a more efficient recycling approach which addresses the shortcomings identified 
above to effectively maximise the recyclability of WEEE and minimise the environmental and economical impacts of its recycling and disposal.

\section{A brief review of most relevant research}

An overview of EOL planning problems in a product life cycle are given by Gungor and Gupta (1999), Fleischmann et al. (1997) and Goggin and Browne (1998). For product recovery and recycling, several decision factors should be considered when determining the maximum environmental benefits that can be achieved for a given economic cost when a product reaches its EOL. These factors include the level of disassembly, sequencing for dismantling operations, the EOL routes for removed components as well as the hulk and the reverse logistics. A number of previous investigations have considered important aspects of recovery optimisation problem. For instance, Johnson and Wang (1998) present a systematic procedure of generating the best disassembly sequence to maximise the profits of material recovery. Penev and de Ron (1996) describe a cost modelling tool to determine an economical disassembly level and disassembly sequence for a specific product. Goggin and Browne (2000a) describe a software model for the decision-support to identify the most favorable route from a cost and value perspective. Lambert (1997) develops a linear optimisation model for an optimum disassembly of complex products. Pnueli and Zussman (1997) suggest a dynamic programming algorithm to solve the disassembly sequencing problem that includes the EOL value of a product.

Remanufacturing represents a higher form of reuse by focusing on environmentally value-added recovery, rather than materials recovery and recycling which have its own disadvantages and environmental impacts. Guide (2000) presents a survey of production planning and control activities at remanufacturing firms and claims that significant changes in production planning and control activities are needed for their use in remanufacturing facilities. Clegg et al. (1995) present linear programming models of production systems with remanufacturing capability to examine the effects of different cost structures on the long-term viability of remanufacturing operations. Ferguson and Browne (2001) examine information requirements for reverse logistics within the Extended Enterprise. 
Some studies have incorporated both cost estimation and environmental impact estimation. For example, Krikke et al. (1998) describe a method on a tactical management level to determine the best recovery and disposal strategy of product type considering technical, economical and ecological criteria. Lee et al. (2001) try to find alternative that can both maximises profit and minimises environmental impact and use a coffee maker as an example. Yu et al. (2000) adopt analytical hierarchic process to find the best recycling strategy in which environmental impact, cost and reclaimed materials were considered as the major criteria for strategy selection. Huisman et al. (2003) describe 'the quotes for the environmentally weighted recyclability' or QWERTY approach which focuses on the determination of environmentally weighted recycling scores. Herrmann et al. (2002) describe a method to calculate economical and ecological indicators to evaluate EEE waste in regards to material recycling, and used life cycle assessment and life cycle costing to calculate these indicators.

The recent publications that deal with decision-support systems for WEEE recycling mainly provide the assessment on macro level. For example, Lamvik et al. (2002) present the AEOLOS methodology to determine the most appropriate EOL option (reuse, material recycling, incineration or disposal) based on economic, environmental and societal criteria. Rose et al. (1999) present a design oriented decision framework which focuses on technical product design variables such as expected life time and number of parts to select an appropriate EOL strategy at the design stage. On the other hand, Goggin and Browne (2000b) describe a taxonomy of electrical and electronic manufacturing situations from a resource recovery perspective to provide an understanding of the recovery and recycling issues. The framework presented in this paper is unique in that it explores multi-objective optimization for generation of process plans for recycling activities. The framework further extends previous research in EOL decision-support systems by considering best possible sets of trade-offs between environmental and economical variables and includes simultaneous consideration of the macro level EOL planning (product reuse, material recycling, disposal) and micro level EOL planning (pre-treatment and depollution, removal of valuable parts and penalty materials, shredding and separation processes). 


\section{An integrated framework for WEEE recycling}

An EOL product may be discarded to landfill, incinerated, disassembled for material reclamation, collected and examined for possible refurbishment and reuse, or indeed a combination of these activities may occur. Each EOL option incurs economical and environmental costs and creates potential value. There are many factors that influence the selection of the most appropriate EOL strategy including environmental impact, legislative compliance, market competition, as well as the impact on brand image, product design complexity and material composition. The integrated recycling process planning framework presented in this paper aims to assist designers, manufacturers and EEE recycling facilities in determining the bespoked end-of-life recycling process route for an individual product (or product family) in WEEE. It is argued that such systematic approach to developing a bespoke recycling process plan minimises the environmental impacts of EOL management in a technically feasible way and at a reasonable cost. Figure 1 provides an overview of the various stages of the Recycling Process Planning (RPP) framework.

\section{[Insert Figure 1]}

The activities within the RPP framework begin with the product evaluation stage to identify the components of interest and the material composition within the product (see Figure 2). This product information is then used to identify the various requirements for legislative compliance and specific pre-treatment processes. Subsequently, a recycling process planning stage identifies the specific product recovery and recycling processes to suit a particular EEE product scenario. Finally the Ecological and Economical (Eco2) assessment stage analyses the environmental and economical impacts associated with the EOL processes proposed by the RPP framework. The tasks involved in each stage of the RPP framework are described in more detail below.

\section{[Insert Figure 2]}




\subsection{Product evaluation}

The first stage of the RPP framework, namely the product evaluation, identifies the main design and material characteristics of the product. Product evaluation is needed to classify the product into a particular WEEE category according to Annex 1A of the WEEE directive and to identify the crucial factors that determine the selection of a recovery option. There are four main tasks involved in product evaluation. The first task determines the hazardous and toxic substances present in the product. This evaluation is essential for the selection of appropriate pre-treatment processes in order to comply with the requirements of Annex 1B of the WEEE directive related to the treatment of hazardous materials. The second and third tasks determine the valuable/reusable components and penalty (contaminating) materials in the product. Removal of valuable and reusable components before destructive disassembly can also improve the eco-efficiency of the product recycling provided that the environmental gain from this disassembly overweighs removal cost. Similarly, removal of penalty materials can improve the value of the hulk. For example, removal of copper wires improves the value of the scrap steel. Finally in the fourth task, material composition of the product is identified and the product hulk is divided into material streams like ferrous metals, non ferrous metals, plastics, glass etc. Based on this material composition appropriate shredding and mechanical separation processes are assigned. The information collected and processed as part of the product evaluation stage is used to support the remaining stages in the RPP framework as outlined below.

\subsection{Legislative compliance monitoring}

The second stage of the RPP framework identifies the legislative requirements related to the recycling of the product under consideration. WEEE directive requires recovery and recycling targets ranging from $50 \%$ to $80 \%$ by product weight to be met across ten categories of electrical and electronic equipment as shown in Table 2. In addition to meeting certain recovery and recycling targets, the directive also requires specific treatment and recovery methods to be followed for individual products. For example, the removal of CRT from which the fluorescent coating must be removed, plastic containing brominated flame retardants and gas discharge lamps 
from which the mercury must be removed etc. Similarly, the Restriction Of the use of certain Hazardous Substances (RoHS) directive requires prevention of the use of lead, mercury, cadmium, hexavalent chromium, polybrominated biphenyls and polybrominated diphenyl ether in EEE. In the compliance monitoring stage, the detailed product information identified through product evaluation stage is utilised to assess the product characteristics against the WEEE and ROHS directives requirements. The legislative compliance information is then passed to the recycling process planning stage in order to assist with the selection of the appropriate recovery and recycling processes.

\section{[Insert Table 2]}

\subsection{Recycling process planning}

The third stage of the RPP framework generates bespoked recycling process plans for an individual EEE product. The recycling process planning stage aims to take advantage of the benefits provided by a systematic approach to process planning experienced in manufacturing applications (Marri et al. 1998) and apply a similar principle to increase the efficiency of recycling activities. There are two basic approaches to process planning, namely generative and variant approach. The generative approach to process planning is based on developing a completely new plan for every product (or its parts and components). It uses the decision logic, formulae, algorithms and geometric analysis and is considered to be more suitable for developing process plans for complex and novel product designs. On the other hand in the variant approach to process planning, a standard plan is modified to suit the given product. The standard plan is usually developed for a complex product that incorporates all the features of a particular group or family of products. The process plan for product under consideration is compiled by retrieving those sections of the standard plan that are relevant.

In case of recycling process planning of WEEE, nature and range of processes are not as complicated as in manufacturing and do not require generation of completely new plans (as in generative approach) for different materials and components in WEEE. In addition, there is a huge 
potential for the reuse of subsets of the recycling process plans among WEEE due to the inherent parts and products commonality between different EEE products. Hence, the adaptability and flexibility offered through variant approach justify its application for the recycling process planning. In the RPP framework based on the product categories used in the WEEE directive, a number of standard recycling process plans have been developed and used for generation of bespoke recycling process plans for individual products. The generation of the standard recycling process plans is supported by a central database consisting of a list of all contemporary recycling processes used in WEEE recycling and their associated environmental and economical impacts. A standard recycling process plan for a specific category of EEE consists of a wide range of recovery and recycling processes to cater for the variety of electrical and electronic products in that category together with broad range of components and substantial differences in material composition among those products. It is claimed that the utilisation of the variant approach to recycling process planning allows for the adoption of different EOL strategies (reuse, refurbishment, material recycling, incineration and disposal) for different components and materials contained in a product to improve the overall performance of WEEE recycling.

\subsection{Ecological and economical assessment}

The final stage of the RPP framework is the Eco2 assessment which compares the environmental and economical impacts of various EOL options for WEEE. This assessment is important in order to determine the best EOL route for specific product and to prioritise the recovery and recycling processes based on their eco-efficiency. The Eco-Indicator 99 methodology (PRE Consultants 2000), which is a damage oriented life cycle assessment method, has been used to calculate the environmental impacts associated with each EOL process. In this methodology all environmental effects are translated to actual damage inflicted to eco-system quality, human health and resource depletion. Human health and ecosystem quality are considered to be of almost equal importance, while resources are considered to be half as important. The final result in this methodology is expressed in a single score (i.e. a point) that indicates the overall damage to the environment and is easier to interpret than the conventional LCA results. In the Eco-Indicator 99 methodology, one point is representative for one thousandth of the yearly environmental load of one average 
European inhabitant. Based on this methodology, an upper and lower limit of environmental impact is calculated as part of Eco2 assessment to provide a scale for the evaluation of the actual environmental impacts associated with a specific recycling process plan. The upper limit of environmental performance is based on the assumption that all materials can be recovered (zero landfilling) without any environmental burden whereas the lower limit of environmental performance assumes all materials in the product will end up in the landfill. Provisions are made for the material degradations and process inefficiencies to be considered while calculating the actual environmental impacts associated with a recycling process plan and with other EOL options.

A parametric cost modelling approach is used to calculate the economical impacts associated with product recycling. All respective EOL processes are quantified according to the different costs, e.g. disassembly cost, processing cost, disposal cost and material revenues, and by summing up all the relevant costs and revenues, the actual economical performance is calculated. An upper (best case scenario) limit of economical performance related to $100 \%$ recovery and recycling of all material contents and a lower (worst case scenario) limit of economical performance related to the cost of sending the complete product to landfill are defined and used to evaluate the actual economical performance of different recycling process plans. Finally, the eco-efficiency of different EOL options, which is a ratio of environmental benefit to unit cost, is calculated to aid the decision making involved in selecting the most suitable end-of-life processes for WEEE.

\section{A Computer-Aided Recycling Process Planner}

The generation of the above-mentioned eco-efficient recycling process plans for WEEE is a complex task which involves concurrent consideration of product and process data related to a wide range of EOL issues such as varying material composition, weight and product structure, product age and condition, various recycling processes and technologies and their environmental and economical impacts. This requires a significant amount of data processing and decision making. Therefore, a Computer-Aided Recycling Process Planning (CARPP) system is developed based on the RPP framework described in Section 5. The CARPP system consists of a user 
interface module, a database module, a recycling process planning module and an assessment module as shown in Figure 3.

\section{[Insert Figure 3]}

The user interface module receives and controls the user input and gives access to the CARPP output. The interface has been developed in Microsoft Visual Basic 6 and integrated with Microsoft Access (used to develop the Database module). The main menu of the user interface module (shown in Figure 4) is split into three parts, namely the generation of a new recycling process plan, the environmental assessment of a recycling process plan, and the economical assessment of a recycling process plan.

\section{[Insert Figure 4]}

The generation of a new recycling process plan conducts the product evaluation, which can then be used by other modules of the CARPP in order to generate bespoke recycling process plans along with the ecological and economical impact assessment results. The product evaluation process within the user interface module starts by identifying the end-of-life product and its category according to the WEEE directive to establish the legislative requirements for the product (Figure 5a). An indicative weight is assigned to the product which can then be used to calculate the recovery and recycling targets for the product. Once a product is selected, the user is then asked to confirm the hazardous and toxic substances present in the product (Figure 5b). These identified hazardous and toxic substances trigger the appropriate pre-treatment processes to be included in the product's bespoke recycling process plan. The third evaluation task within the user interface module identifies the valuable materials and components present in the product (Figure 5c). In order to improve the value of post fragmentation material streams, the product evaluation process identifies the penalty materials and components present in the product to be removed before sending the product to fragmentation process (Figure 5d). Once the information about various 
hazardous, valuable and penalty materials included in the product is collected, material composition of the product is identified and the product hulk is divided into different material streams such as ferrous/non-ferrous metals, plastics, glass etc (Figure 5e). This distribution is based on the generic composition of WEEE and the user can adjust the composition data to suit a specific product. The material mix information is used to identify the appropriate post fragmentation recycling processes for the product under consideration. The final task in the product evaluation identifies the safe disposal processes to be used for the product under consideration (Figure 5f). The inefficiencies of the mechanical separation processes and economic concerns over the available recycling technologies necessitate the disposal of the remaining residue through incineration and/or landfill. Certain hazardous substances removed from WEEE also require safe disposal. The CARPP is able to assign landfill process to certain materials in the WEEE which are not suitable for incineration in view of the toxic nature of the flue gas residues.

\section{[Insert Figure 5]}

The screenshots in Figure 5(b), 5(c) and 5(d) display different hazardous, valuable and penalty materials and components along with their indicative weights present in the product under consideration. An extensive product database containing information about different electrical and electronic products included in WEEE supports this identification process. At the same time, the user interface of the CARPP provides users with a manual data input option for additional materials and components of interest which have not been included in the database. Furthermore, it allows users to alter the indicative weights of proposed materials and components.

The information obtained through the user interface is passed to the database module and the recycling process planning module. The database module stores a variety of different EOL information (e.g. product data, process data and legislative requirements data) and provides access to this information to other modules in the CARPP system. Any new product information obtained during product evaluation is also added to the respective database within the database module. The product database contains information about product characteristics, its WEEE category, weight, 
material composition and components. The process database consists of a list of all contemporary recycling processes used in WEEE recycling and their associated environmental and economical impacts including environmental impacts for material recycling, incineration and landfill as well as dismantling times and costs, processing costs, disposal costs and material revenues. The legislation database contains information about WEEE and ROHS directive and includes recovery targets, recycling targets and pre-treatment requirements.

The recycling process planning module generates the bespoked recycling process plans for WEEE, and it is based on a central database which is linked to the other modules of the CARPP. The central database contains standard recycling process plans for different categories of electrical and electronic products included in WEEE. The information obtained through the product evaluation is used within the recycling process planning module to customize the appropriate standard recycling process plan into a bespoke recycling process plan based on a variant approach to process planning (see section 5.3). The standard recycling process plan consists of the following five main categories of operations:

- De pollution for legislative compliance

- Dismantling for value recovery

- Dismantling to remove penalty substances

- Shredding and mechanical separation to recover different material streams

- Disposal / Landfill

Each of these operation categories in recycling process plans consists of a number of relevant suboperations i.e. specific recovery and recycling processes. These processes are linked to different product design and material characteristics, as well as legislative compliance requirements identified in the first and second module of the CARPP system. For example in case of a refrigerator, the presence of insulation identified during product evaluation stage will trigger the addition of the specific recovery process related to the removal of insulation in the recycling process plan. A typical recycling process plan for a refrigerator is shown in Figure 6. 


\section{[Insert Figure 6]}

The Eco2 assessment module of the CARPP system provides an insight to environmental and economical impacts of a recycling process plan, before it is selected for implementation. The assessment module generally considers three end-of-life options namely, recycling through shredding (current recycling practice), recycling through recycling process plan (as suggested by CARPP) and landfilling,. The assessment process starts with the calculation of the performance limits which provide a scale for the evaluation and assessment of the actual ecological and economical performance of different end-of-life options available for product recycling. It should be noted that the upper performance limit is the best case scenario and represents the environmental gain (usually a negative Eco-Indicator 99 value) related to the use of recycled rather than virgin material. The lower limit is the worst case scenario (usually a positive Eco-Indicator 99 value) and represents the environmental burden related to sending the complete product to landfill. Figure 7 presents the calculation of the upper and lower limit of environmental performance for the refrigerator.

\section{[Insert Figure 7]}

The actual environmental performance of a recycling process plan is calculated by considering the impact of each individual recycling process included in the plan. Material weights and grades and their EOL destinations as well as the process efficiencies of separation processes are considered while calculating the actual environmental performance of the recycling processes. Figure 8(a) depicts the environmental impact assessment of the recycling process plan for the refrigerator. The second part of the Eco2 assessment module enables the economical assessment of the recycling process plan. In a similar way, an upper and lower economical performance limit are defined before calculating the actual economical impacts of different EOL options. Data about the costs and revenues (negative cost) of different recovery and recycling processes is retrieved from the 
database module. Figure 8(b) depicts the calculation of the economical impact of the current recycling practice for the refrigerator.

Finally, the environmental and the economical performance measures are combined to calculate the eco-efficiency, which is a ratio of environmental benefit to unit cost involved. The eco-efficiency scores for different EOL options for a refrigerator are plotted on a two-dimensional environmentcost diagram (Figure 8d). This eco-efficiency diagram clearly highlights the significant environmental and economical impacts of landfilling option in comparison to the current practices and the end-of-life options included in the bespoke recycling process plan generated for the refrigerator. Furthermore, the eco-efficiency diagram also underline the substantial improvement that could be achieved in the environmental and economical performance of WEEE recycling activities through adoption of a systematical approach for generation of a recycling process plan based on the most up-to-date information and knowledge on recycling processes, contained within the CARPP. Finally, the authors argue that though the CARPP is currently developed for the application of WEEE recycling, the underlying principal could easily be reapplied for various manufacturing sectors with complex end-of-life management options for their post-consumer waste.

\section{[Insert Figure 8]}

\section{Concluding Remarks}

The large amount of WEEE produced every year, the legislative pressures to divert this waste from the landfills as well as the high residual value of the materials contained in this waste will significantly impact the EOL management of EEE. The authors argue that the current ad hoc approaches to WEEE recycling will not provide the long-term solutions for environmentally friendly and economically justifiable recovery activities in this sector. Furthermore, one of the recent trend in EEE products has been the reduction of the amount of precious metals (gold, 
palladium, silver, etc) contained in these products to reduce the manufacturing cost. The recovery of these precious metals has been one of the main economic motivations in current EEE recovery and recycling practices. This further highlights the need to improve the environmental and economical performance of WEEE recovery activities to ensure long-term sustainability of EEE recovery sector. The research reported in this paper has presented a novel computer-aided recycling process planning system to determine the most suitable EOL options for WEEE.

It is proposed that the utilisation of CARPP system within the EEE recovery facilities can increase value recovery, introduce process consistency and improve the development of bespoke recycling process plans which are based on the most updated product information and knowledge related to existing recycling processes. These recycling process plans can then be stored in an operational database and applied to similar product families in the future.

A further use of the CARPP system which currently being investigated is as the operational support on the shop floor within the contemporary semi-automated recovery facilities to provide detailed and dynamic instructions via live computer platform to operators. These facilities are being set up in various EU countries to process a large volume of a wide range of EEE products in response to the requirement for massive increase in recovery capacity to meet the targets set by the WEEE directive. Such facilities are expected to process a wide range of WEEE through a semi-automated de-pollution/disassembly line before hulks are sent for shredding and material separation, and therefore the provision of timely information on the required processes to operators will significantly improve the throughput time and consequently the revenues from these facilities. Finally, the authors are of the opinion that the information and knowledge contained in the CARPP system will provide invaluable support for the design of future electrical and electronic products to improve their EOL recovery performance. 


\section{References}

Clegg, A. J., Williams, D. J. and Uzsoy, R., 1995. Production planning for companies with remanufacturing capability. In Proceedings of the IEEE International Symposium on Electronics and the Environment, Orlando, FL, USA.

Cui, J. and Forssberg, E., 2003. Mechanical recycling of waste electric and electronic equipment: a review. Journal of Hazardous Materials, 99(3), 243-263.

Edwards, C., Bhamra, T. and Rahimifard, S., 2006. A Design Framework for End-of-Life Vehicle Recovery. In Proceedings of 13th CIRP International Conference on Life Cycle Engineering, Leuven, Belgium.

European Commission. 2000. Proposal for a directive of the European Parliament and of the Council on Waste Electrical and Electronic Equipment and on the restriction of the use of certain hazardous substances in electrical and electronic equipment, $\operatorname{COM(2000)} 347$ Final, Brussels.

European Commission. 2003. Directive 2002/96/EC of the European Parliament and of the Council. Official Journal of the European Union, L 37/24.

Ferguson, N. and Browne, J., 2001. Issues in end-of-life product recovery and reverse logistics. Production Planning \& Control, 12(5), 534-547.

Fleischmann, M., Bloemhof-Ruwaard, J. M., Dekker, R., van der Laan, E., van Nunen, J. and Van Wassenhove, L. N., 1997. Quantitative models for reverse logistics: A review. European Journal of Operational Research, 103(1), 1-17.

Goggin, K. and Browne, J., 1998. Electronic products recovery-PAWS, a BRITE-EURAM project. Computers in Industry, 36(1-2), 65-74.

Goggin, K. and Browne, J., 2000a. The resource recovery level decision for end-of-life products. Production Planning and Control, 11(7), 628-640.

Goggin, K. and Browne, J., 2000b. Towards a taxonomy of resource recovery from end-of-life products. Computers in Industry, 42(2-3), 177-191.

Guide, V. D. R., 2000. Production planning and control for remanufacturing: industry practice and research needs. Journal of Operations Management, 18(4), 467-483.

Gungor, A. and Gupta, S. M., 1999. Issues in environmentally conscious manufacturing and product recovery: A survey. Computers \& Industrial Engineering, 36(4), 811-853.

Herrmann, C., Eyerer, P. and Gediga, J., 2002. Economic and ecological material index for end of life and design of electronic products. In Proceedings of IEEE International Symposium on Electronics and the Environment, San Francisco, USA.

Huisman, J., Boks, C. B. and Stevels, A. L. N., 2003. Quotes for environmentally weighted recyclability (QWERTY): concept of describing product recyclability in terms of environmental value. International Journal of Production Research, 41(16), 3649-3665. 
ICER. 2005. Status report on WEEE in the UK, Interim report by ICER. Industry Council for Electronics Recycling, London

Johnson, M. R. and Wang, M. H., 1998. Economical evaluation of disassembly operations for recycling, remanufacturing and reuse. International Journal of Production Research, 36(12), 3227-3252.

Krikke, H. R., Harten, A. and Schuur, P. C., 1998. On a medium term product recovery and disposal strategy for durable assembly products. International Journal of Production Research, 36(1), 111-139.

Lambert, A. J. D., 1997. Optimal disassembly of complex products. International Journal of Production Research, 35(9), 2509-2524.

Lamvik, T., Myklebust, O. and Miljeteig, G., 2002. The AEOLOS Methodology. In Proceedings of the IEEE International Symposium on Electronics and the Environment, San Francisco, USA.

Lee, S. G., Lye, S. W. and Khoo, M. K., 2001. A Multi-Objective Methodology for Evaluating Product End-of-Life Options and Disassembly. The International Journal of Advanced Manufacturing Technology, 18(2), 148-156.

Macauley, M., Palmer, K. and Shih, J. S., 2003. Dealing with electronic waste: modelling the costs and environmental benefits of computer monitor disposal. Journal of Environmental Management, 68, 13-22.

Marri, H. B., Gunasekaran, A. and Grieve, R. J., 1998. Computer-aided process planning: A state of art. The International Journal of Advanced Manufacturing Technology, 14(4), 261-268.

Penev, K. D. and de Ron, A. J., 1996. Determination of a disassembly strategy. International Journal of Production Research, 34(2), 495-506.

Pnueli, Y., 1997. Evaluating the end-of-life value of a product and improving it by redesign. International Journal of Production Research, 35(4), 921-942.

PRE Consultants. 2000. Eco-indicator 99 Manual for designers - A damage oriented method for life cycle assessment. Available from: http://www.pre.nl/download/EI99_Manual.pdf [Accessed 22 November 2006].

Rose, C. M., Beiter, K. A. and Ishii, K., 1999. Determining end-of-life strategies as a part of product definition. In Proceedings of the IEEE International Symposium on Electronics and the Environment, Danvers, USA.

Yu, Y., Jin, K., Zhang, H. C., Ling, F. F. and Barnes, D., 2000. A decision-making model for materials management of end-of-life electronic products. Journal of Manufacturing Systems, 19(2), 94-107. 


\section{$\underline{\text { List of Figures }}$}

Fig. 1 Stages in the recycling process planning framework

Fig. 2 The tasks involved in the generation of recycling process plan

Fig. 3 Architecture of the CARPP system

Fig. 4 Main menu of the CARPP system

Fig. 5 User interface module of the CARPP system

Fig. 6 A typical recycling process plan for refrigerator

Fig. 7 Environmental performance limits for refrigerator recycling

Fig. 8 The Assessment module of the CARPP system

\section{List of Tables}

Table 1 Arisings of domestic WEEE in the UK

Table 2 Recovery and recycling targets for WEEE 
Table 1

\begin{tabular}{|c|c|c|c|c|}
\hline Categories of WEEE & $\begin{array}{l}\text { Tonnage discarded } \\
\text { Tonnes (x 1000) }\end{array}$ & $\begin{array}{c}\text { Per cent } \\
\text { (Total Weight) }\end{array}$ & $\begin{array}{l}\text { Units discarded } \\
\text { (millions) }\end{array}$ & $\begin{array}{c}\text { Per cent } \\
\text { (No. of Units) }\end{array}$ \\
\hline Large household appliances & 644 & 69 & 14 & 16 \\
\hline Small household appliances & 80 & 8 & 30 & 31 \\
\hline IT/Telecommunication equipment & 68 & 7 & 21 & 23 \\
\hline Consumer equipment & 120 & 13 & 12 & 13 \\
\hline Tools & 23 & 2 & 5 & 5 \\
\hline Toys, leisure and sports equipment & 2 & $<1$ & 2 & 2 \\
\hline$\sqrt{2}$ & 2 & $<1$ & 9 & 10 \\
\hline Monitoring and control equipment & $<1$ & $<1$ & $<1$ & $<1$ \\
\hline Total & 940 & 100 & 93 & 100 \\
\hline
\end{tabular}


Figure 1

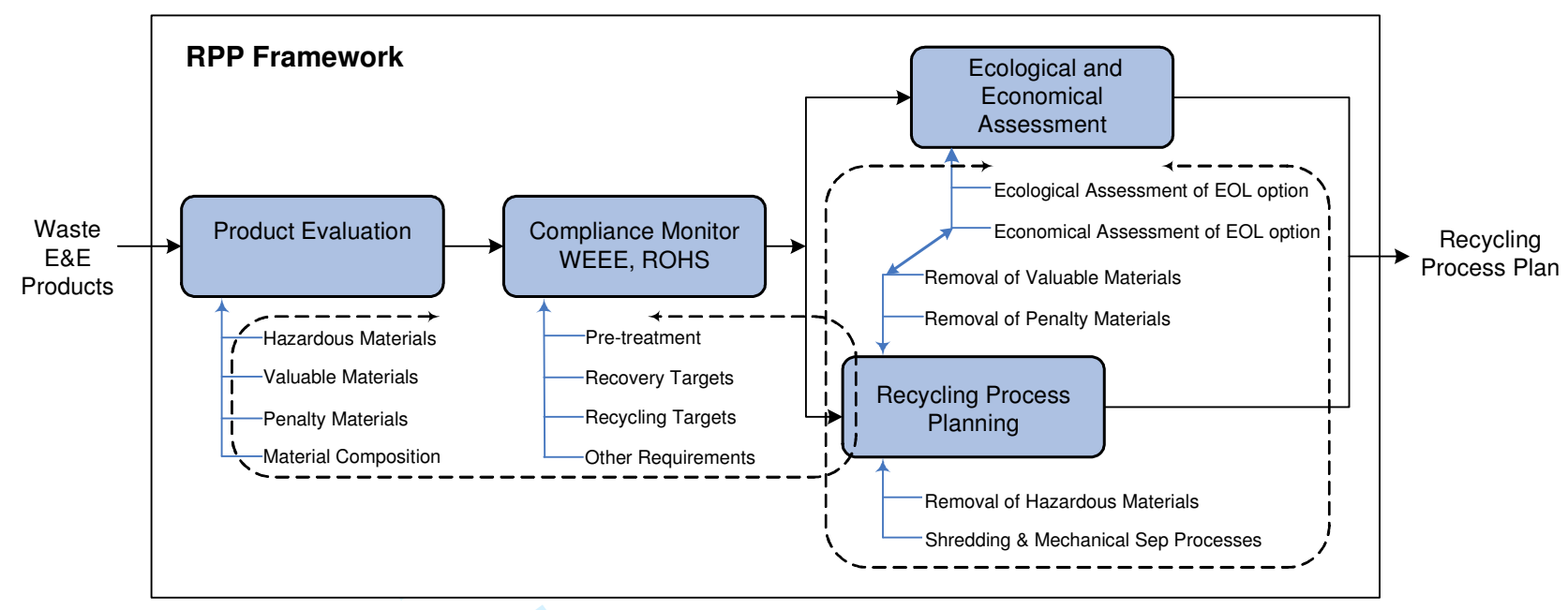


Figure 2

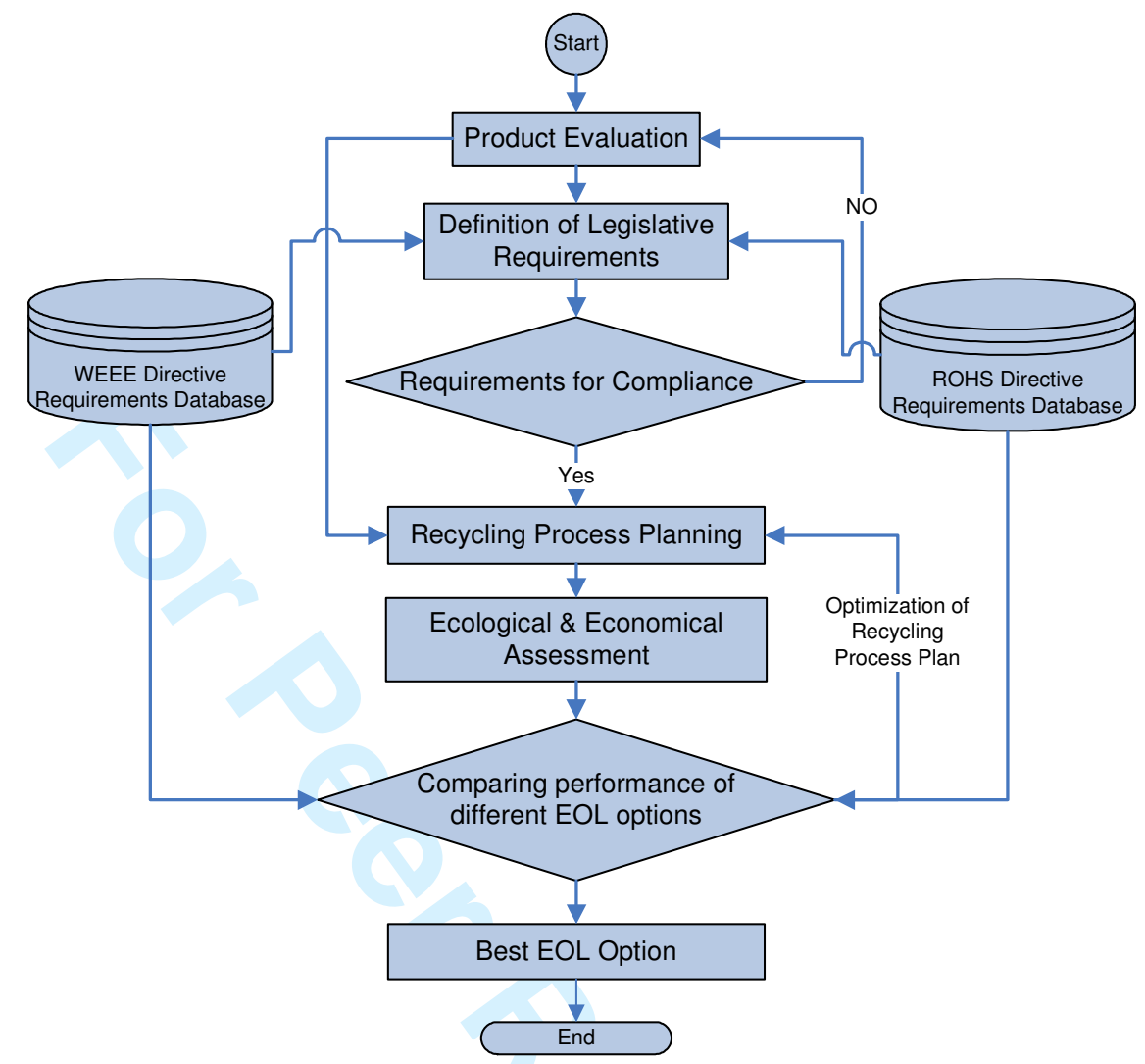


Table 2

\begin{tabular}{|c|c|c|}
\hline \multirow[b]{2}{*}{ Categories of WEEE } & \multicolumn{2}{|c|}{ Minimum Targets by average weight per appliance } \\
\hline & Recovery & Recycling and Reuse \\
\hline Large household appliances & $80 \%$ & $75 \%$ \\
\hline Small household appliances & $70 \%$ & $50 \%$ \\
\hline IT/Telecommunication equipment & $75 \%$ & $65 \%$ \\
\hline Consumer equipment & $75 \%$ & $65 \%$ \\
\hline Lighting equipment & $70 \%$ & $50 \%$ \\
\hline Electrical and Electronic tools & $70 \%$ & $50 \%$ \\
\hline Toys, leisure and sports equipment & $70 \%$ & $50 \%$ \\
\hline Medical appliances & \multicolumn{2}{|c|}{ No Targets } \\
\hline Monitoring and control equipment & $70 \%$ & $50 \%$ \\
\hline Automatic dispensers & $80 \%$ & $75 \%$ \\
\hline
\end{tabular}


Figure 3

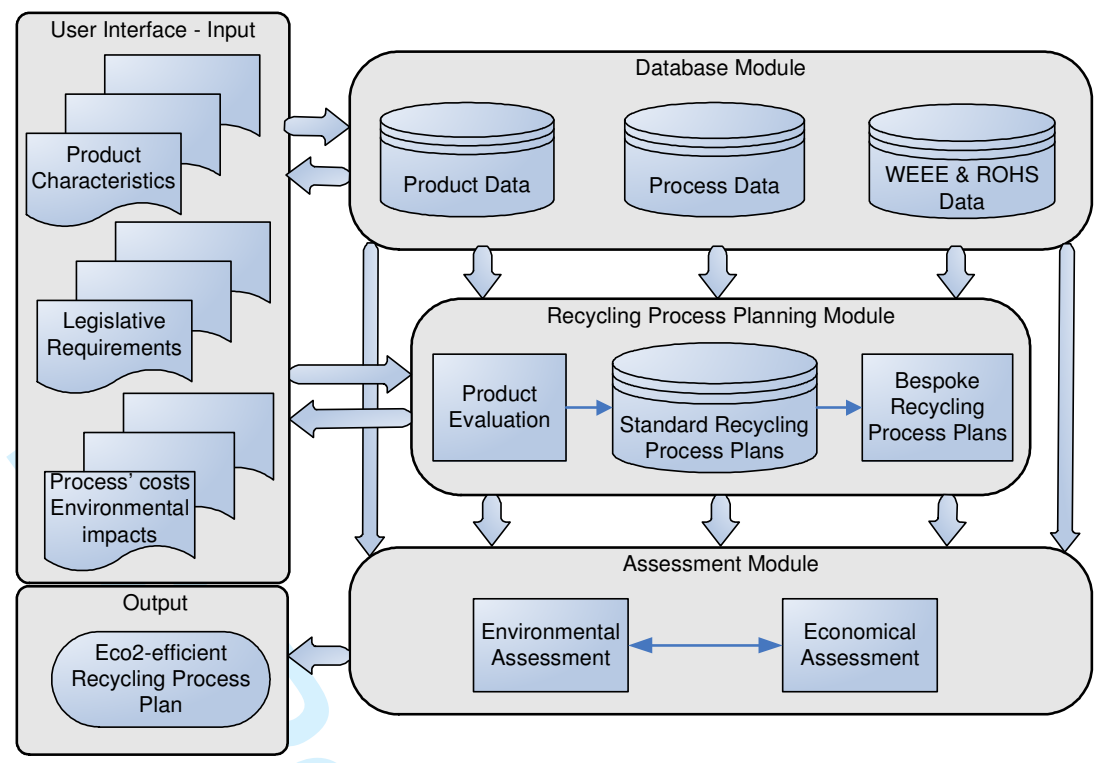


Figure 4

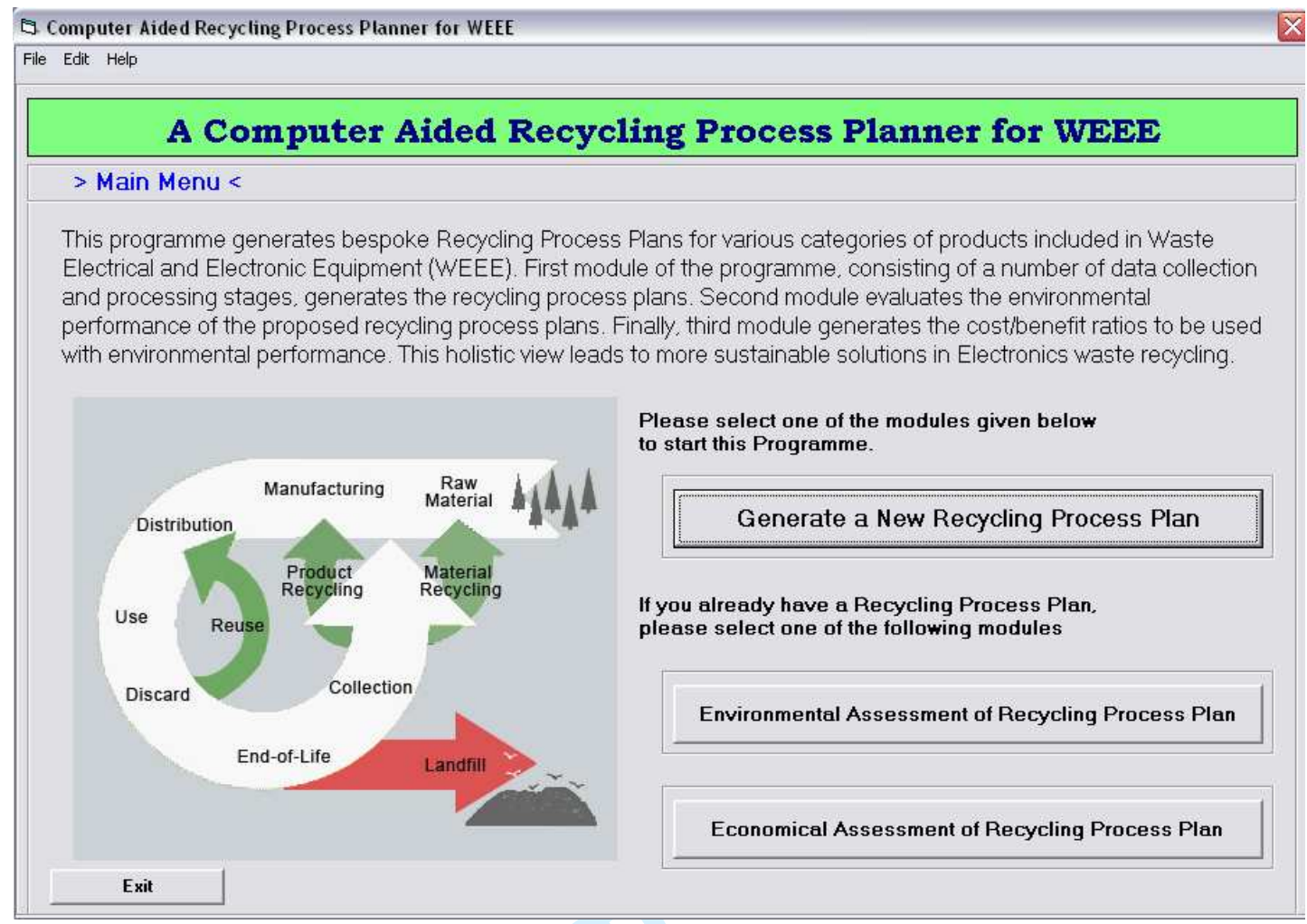


Figure 5

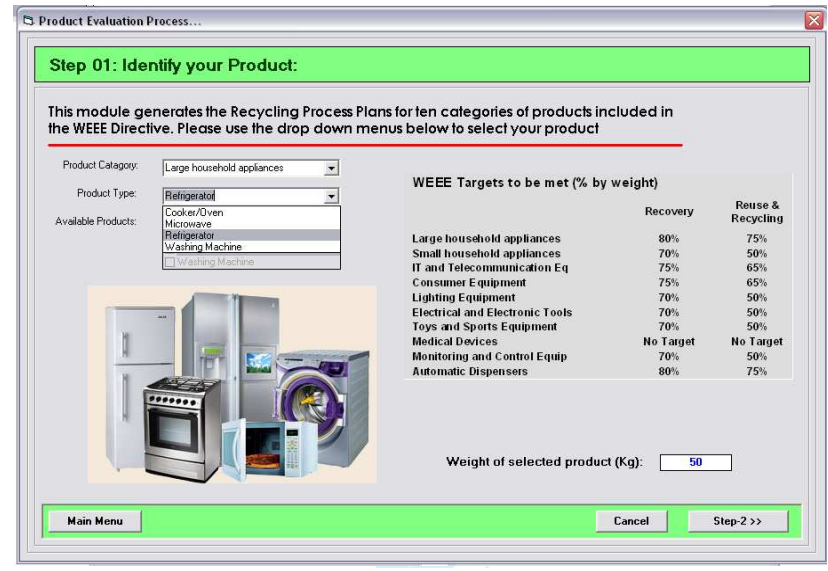

(a) Product identification stage

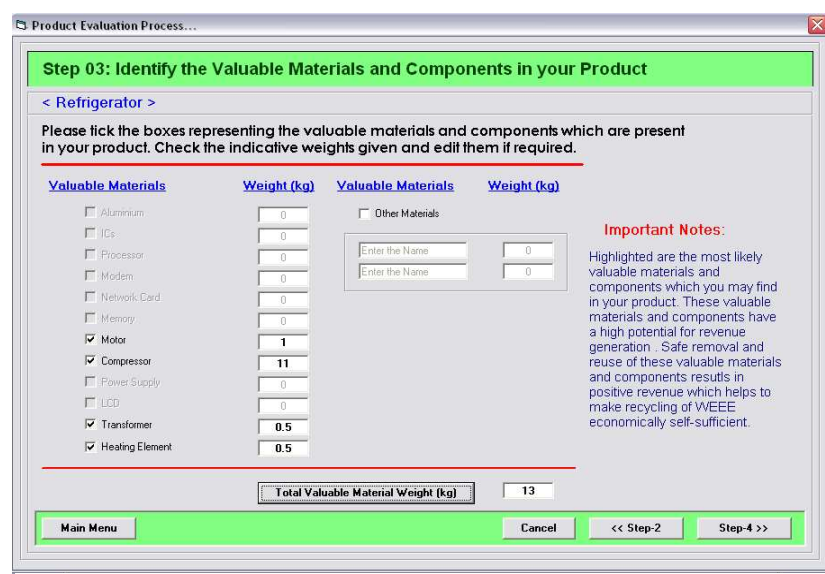

(c) Valuable materials identification stage

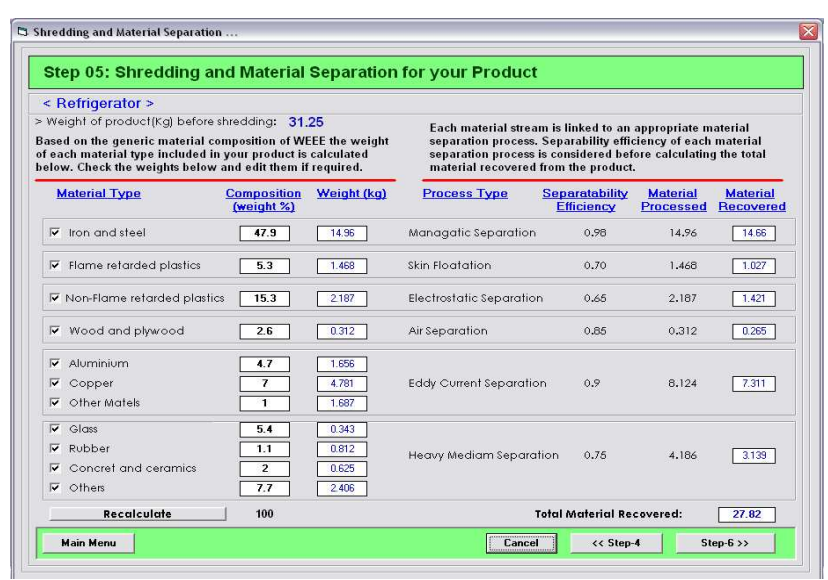

(e) Mechanical separation identification stage

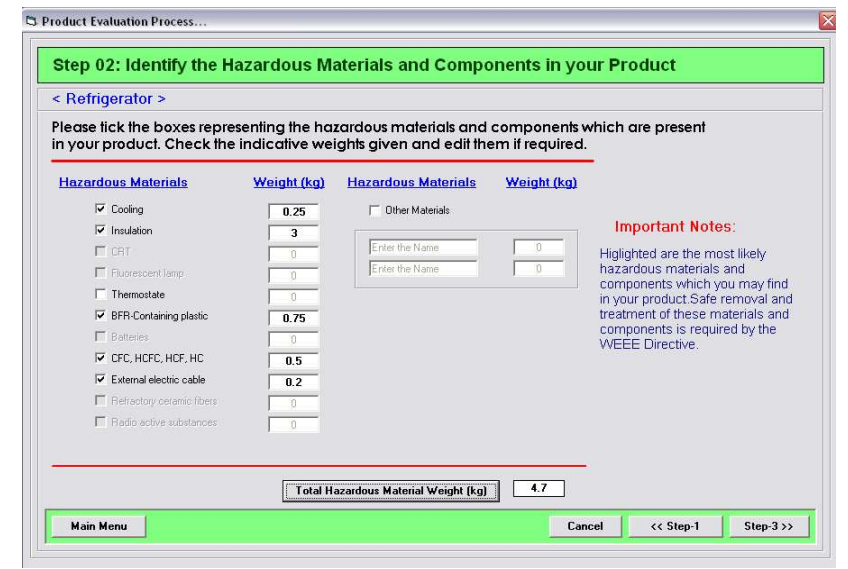

(b) Hazardous materials identification stage

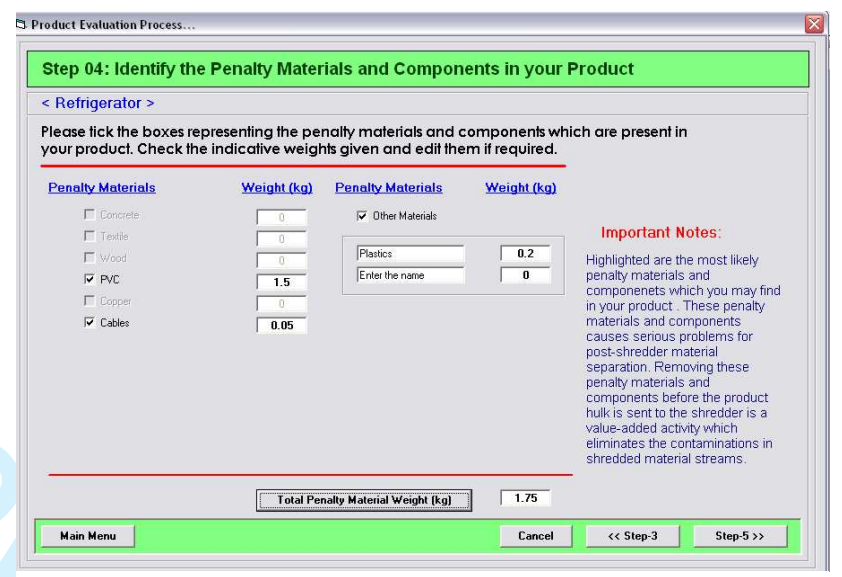

(d) Penalty materials identification stage

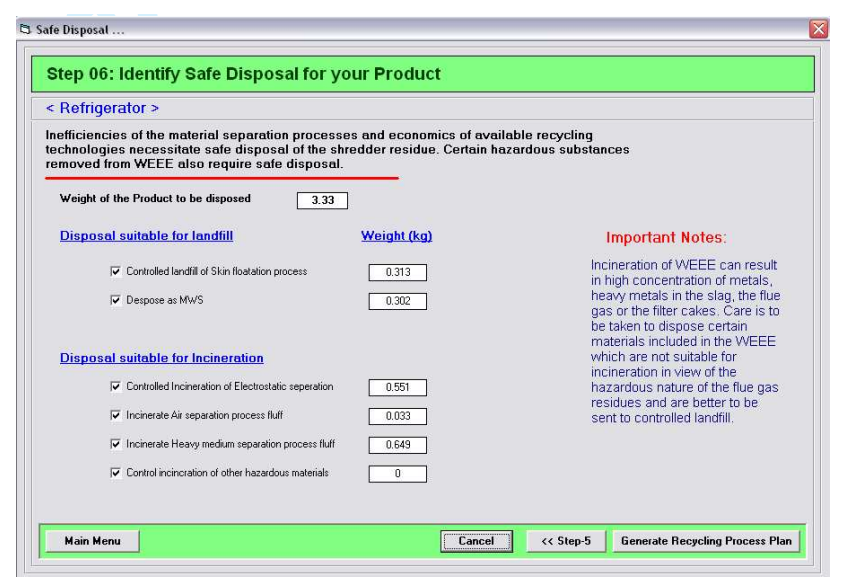

(f) Safe disposal identification stage 
Figure 6

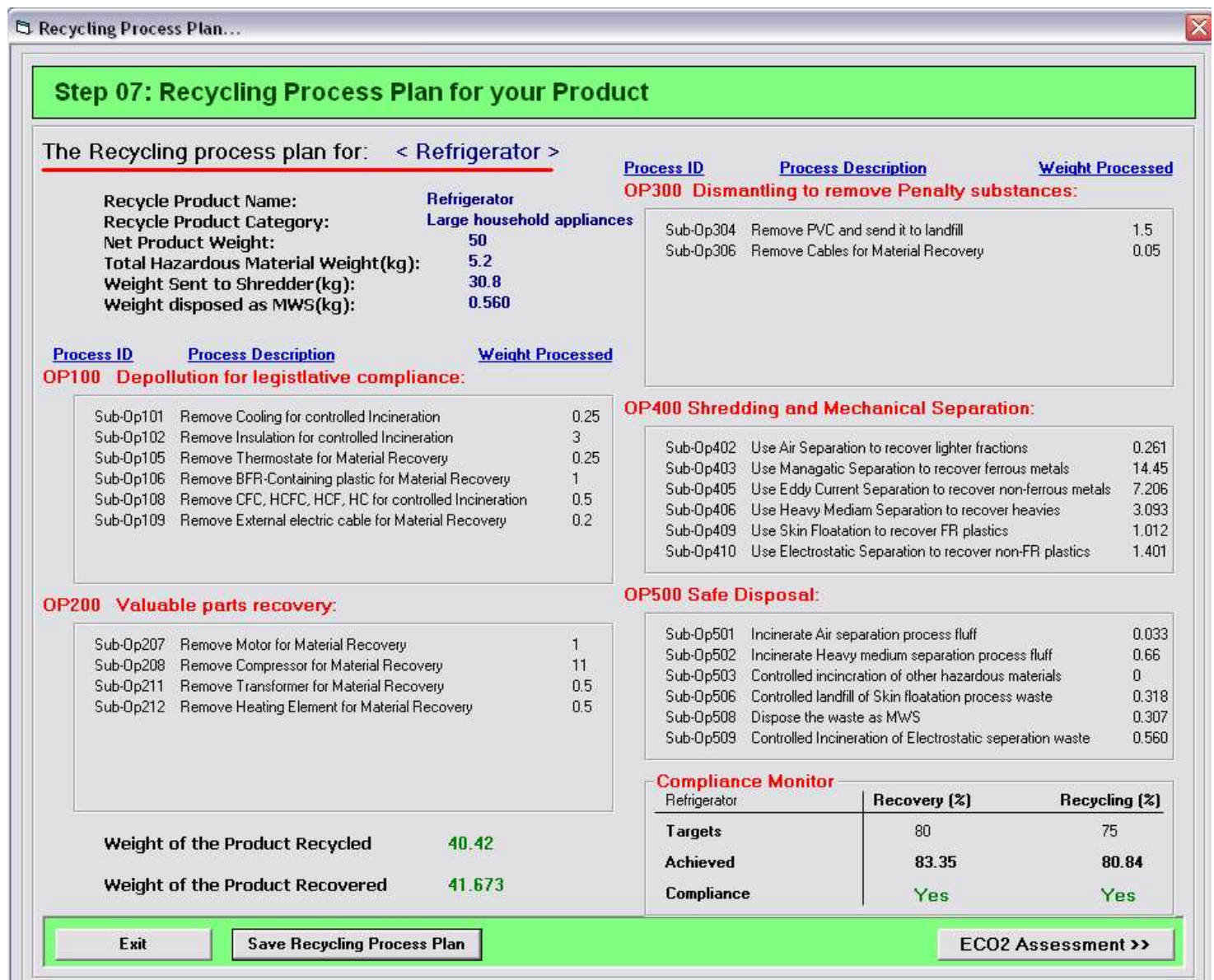


Figure 7

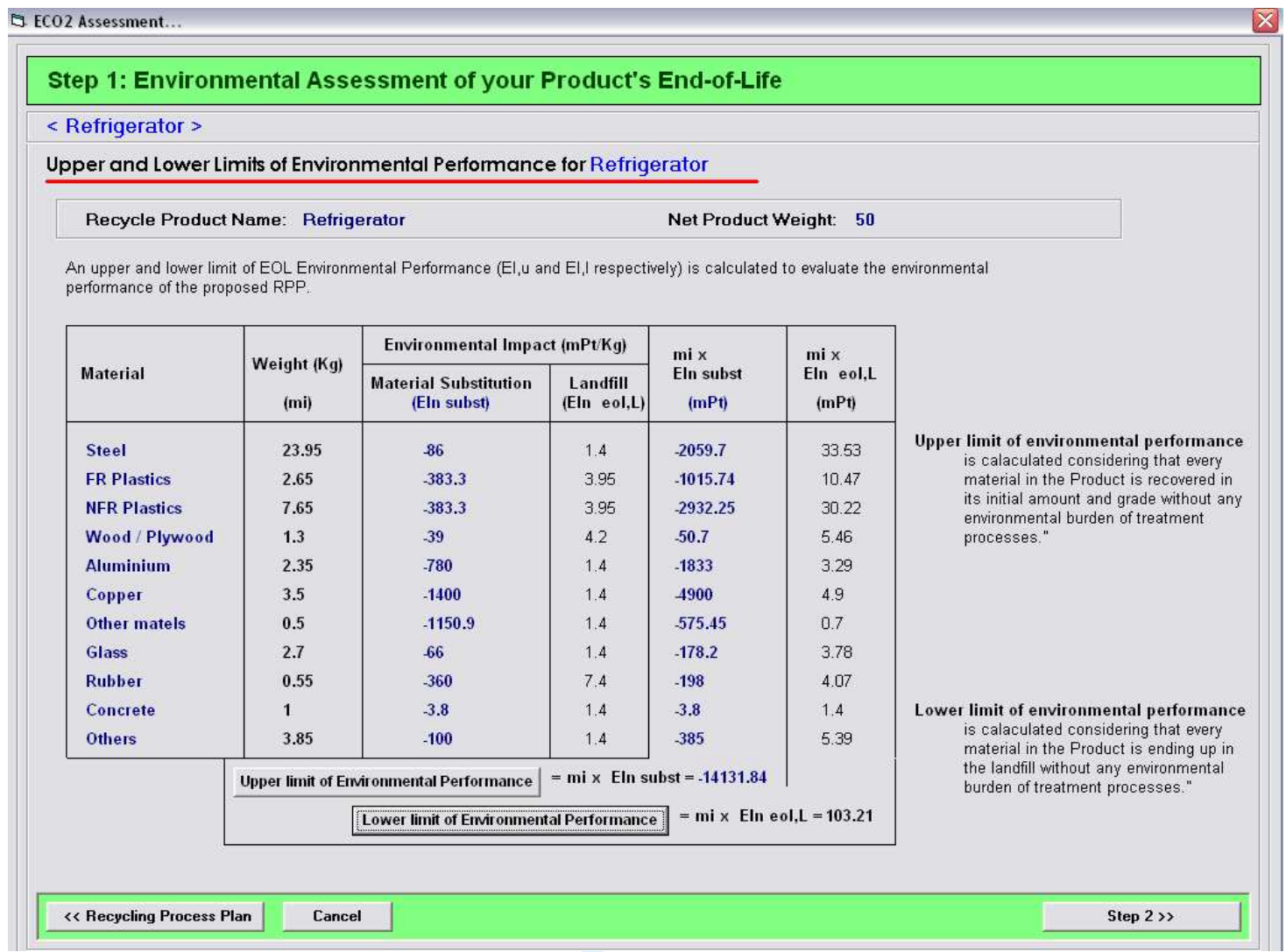


Figure 8

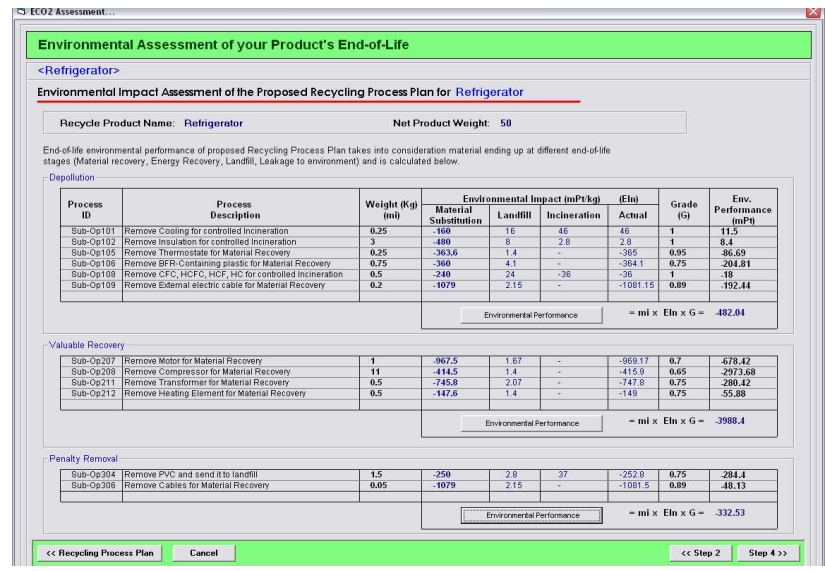

(a) Environmental assessment of the recycling process plan

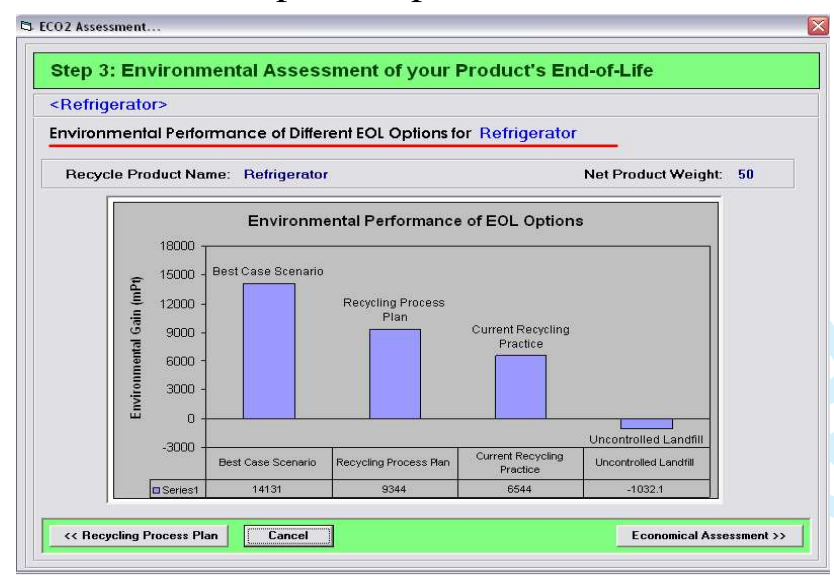

(c) Environmental assessment results

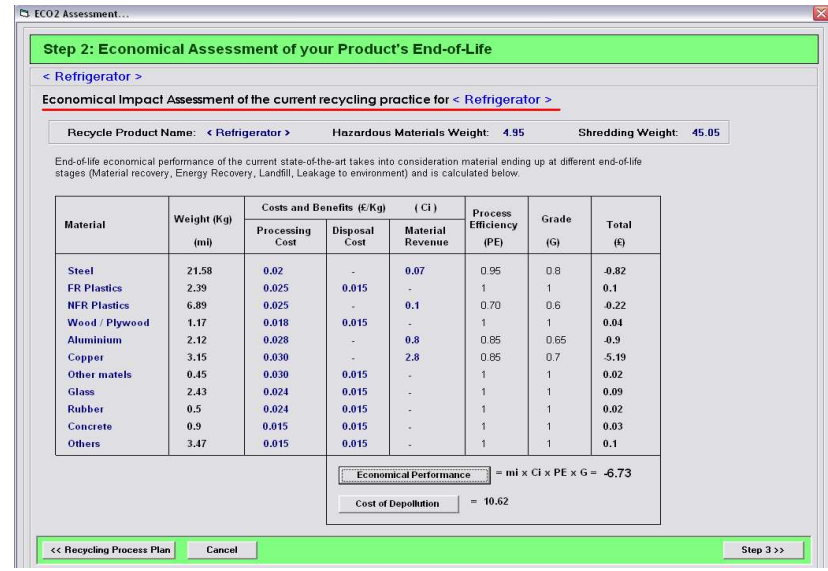

(b) Economical assessment of current recycling practice

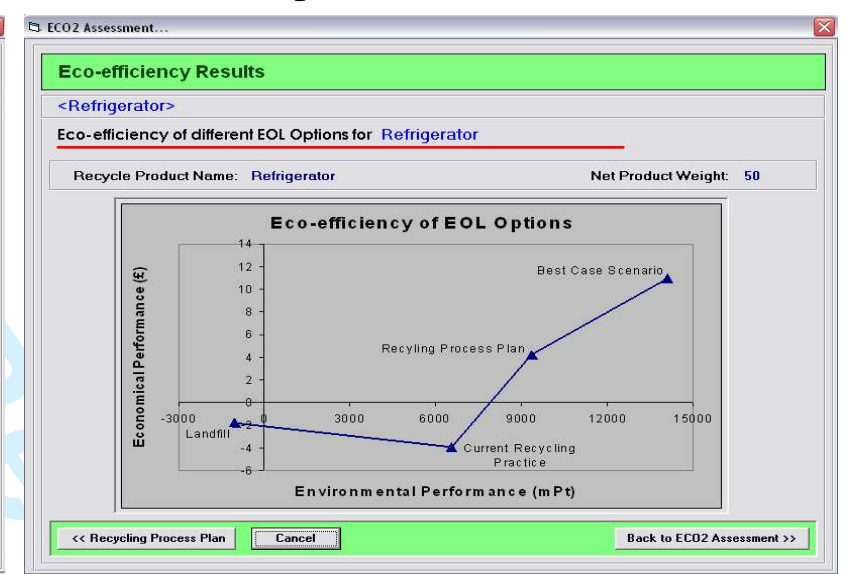

(d) Eco2-efficiency of different EOL options 